\title{
Metal Complexes of $\pi$-Expanded Ligand (7): Syntheses, Structures and Properties of Pt(II) Complexes Containing the Isomeric 1- and 2-Alkyliminomethyl Pyrene Ligands
}

\author{
Xuan-Dien Luong ${ }^{1,2, *}$ and Xuan-Truong Nguyen ${ }^{1}$ \\ 1 School of Chemical Engineering, Hanoi University of Science and Technology, 1 Dai Co Viet, \\ Hanoi 100000, Vietnam; truong.nguyenxuan@hust.edu.vn \\ 2 Department of Chemistry, Graduate School of Science and Engineering, Tokyo Metropolitan University, \\ 1-1 Minami-Ohsawa, Hachi-Oji, Tokyo 192-0397, Japan \\ * Correspondence: dien.luongxuan@hust.edu.vn
}

Received: 18 April 2020; Accepted: 22 May 2020; Published: 3 June 2020

\begin{abstract}
A $[\mathrm{O}, \mathrm{N}]$ bidentate $\pi$-expanded ligand system, (E)-1-( $n$-octylimino)methylpyren-2-ol (2), was newly synthesized via a six-step synthesis from pyrene. The ligand 2 reacts with $\left[\mathrm{PtCl}_{2}\left(\mathrm{PhCN}_{2}\right]\right.$ in chlorobenzene and the presence of a base at reflux for $2 \mathrm{~h}$ under the formation of $(\mathbf{2}(\mathbf{P t}))$ complex with a yield of $70 \%$. The molecular structure of $(\mathbf{2}(\mathbf{P t}))$, studied by common spectroscopic methods and X-ray diffraction, shows a square planar geometry with a trans-configuration of the ligands. The molecular structure, absorption spectra, electrochemical properties, and phosphorescence characteristics of the (2(Pt)) complex are discussed, emphasizing the comparison with those of the previously reported $\mathrm{Pt}$ complex (1(Pt)) containing the isomeric ligands of 2, (E)-2-(n-octylimino)methylpyren-1-ol. The DFT calculations of the two Pt complexes are carried out and exhibit a clear explanation of the relationship between their physico-chemical characteristics.
\end{abstract}

Keywords: coordination chemistry; platinum complex; pyrene; $\pi$-expanded ligand; salicylaldimine

\section{Introduction}

Platinum(II) complexes have attracted much attention due to their applications in electroluminescence, photovoltaics, optical limiting, photocatalysis, and molecular probes, etc. [1-16]. These complexes show a ${ }^{3} \mathrm{MLCT} /{ }^{3} \mathrm{IL}$ mixed triplet excited state, and thus the emission is assigned as phosphorescence, featuring large Stoke shifts and long excited state lifetimes [1,11,17-26]. Although a larger number of platinum(II) complexes with emission spectra that collectively span the completely visible spectrum have now been extensively designed and synthesized, it remains a challenge to obtain species that emit efficiently at the extremes of the spectral range [27].

Our research group has been interested in $\pi$-expanded ligand and the corresponding metal complexes [28,29]. Previously, we already reported one pyrene-based ligand, namely (E)-2-(noctylimino)methylpyren-1-ol (1) and its $\mathrm{Pt}(\mathrm{II})$ and $\mathrm{Pd}(\mathrm{II})$ complexes [28,29]. Reflecting the expanded $\pi$-system of pyrene, for example, these complexes show a bathochromic shift in absorption spectrum compared with simple salicylaldimine complexes [28]. In order to obtain further understanding of pyrene-based ligands and their metal complexes and enhance the photophysical properties of the obtained molecule, we designed an isomer of 1, (E)-1-(n-octylimino)methylpyren-2-ol (2), synthesized the Pt complex of the new ligand, and tried to clarify the differences in the physico-chemical characteristics of the two isomeric Pt complexes.

This research strategy was previously used for salicylaldimine-type ligands based on naphthalene by Calvin in 1948 (Chart 1) [30]. However, the difference in atomic coefficient for the 1- and 2-positions of naphthalene is small; therefore, both complexes do show similar properties. We focused on the 
special characteristics of molecular orbitals such as the 2- and 7-positions of pyrene that are the node of both the HOMO and LUMO of the molecule [31-38]. Therefore, the replacement of the positions of hydroxyl and imine groups would induce a drastic change in the properties of platinum complexes.<smiles>[R]N1C=Cc2ccc3ccccc3c2OC12N([R])C=NC21N=Cc2ccc3ccccc3c2O1</smiles>

$1 "(\mathrm{M})$<smiles></smiles>

2"(M)

Chart 1. Designed complexes by M. Calvin.

In this work, we report the synthesis and characterization of the new isomer $\mathbf{2}(\mathbf{P t})$ of the previous platinum complex 1(Pt) (Chart 2). With the exchange of functional groups at the 2-position and 1-position of the ligand structure, the profound differences in the structural, electronic, and photophysical properties of both obtained isomers were observed.

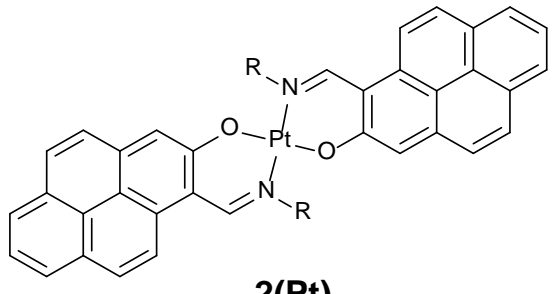

2(Pt)<smiles></smiles>

1(Pt)

Chart 2. Platinum complexes discussed in this paper.

\section{Results and Discussion}

\subsection{Synthesis}

Pyrene is most commonly functionalized at the 1-position because electrophilic substitutions prefer to occur at this position. Generally, the 2-substitued derivatives are obtained through the reduction of pyrene to 4,5,9,10-tetrahydropyrene, substitution, and reoxidation [39], which is both effortful and low yielding. Recently, an Ir(I)-catalyzed C-H borylation developed by Marder and co-workers, has enabled the 2-position to be functionalized at a much higher yield [31-35,37]. As the steric demand of the catalyst restricts the substitution to the 2-position, it allows the regioselective synthesis of the precursor 2-hydroxypyrene [33].

The syntheses of ligand 2 and the corresponding platinum complex 2(Pt) were shown in Scheme 1. The important intermediate, pyrene with the hydroxyl group at 2-position and aldehyde at 1-position is a known compound; we modified the scheme with the mentioned method. By using the $\operatorname{Ir}(\mathrm{I})$ catalyzed borylation, the desired boronic acid ester was obtained at a $49 \%$ yield. A treatment of $\mathrm{H}_{2} \mathrm{O}_{2}$ afforded 2-hydroxypyrene at the excellent yield of 95\%. After the protection of the methoxymethyl (MOM) ether with the chloromethyl methyl ether $(\mathrm{MOMCl})$ in acetone and the presence of potassium carbonate, ether 5 was selectively lithiated with n-butyllithium using the ortho-directing MOM group [40] and quenched with DMF to form the formyl group and afforded 2-methoxymethoxy-1-pyrene carboxaldehyde 4 [41,42]. The obtained molecule shows identical spectroscopic properties with those of the previous report. The imine formation reaction was carried out by the treatment of amine on molecule 3 to afford igand 2. Metallation reactions were carried out with a platinum reagent to produce platinum complex $\mathbf{2}(\mathbf{P t})$, accounting for the stability of the complex and the future applications. 

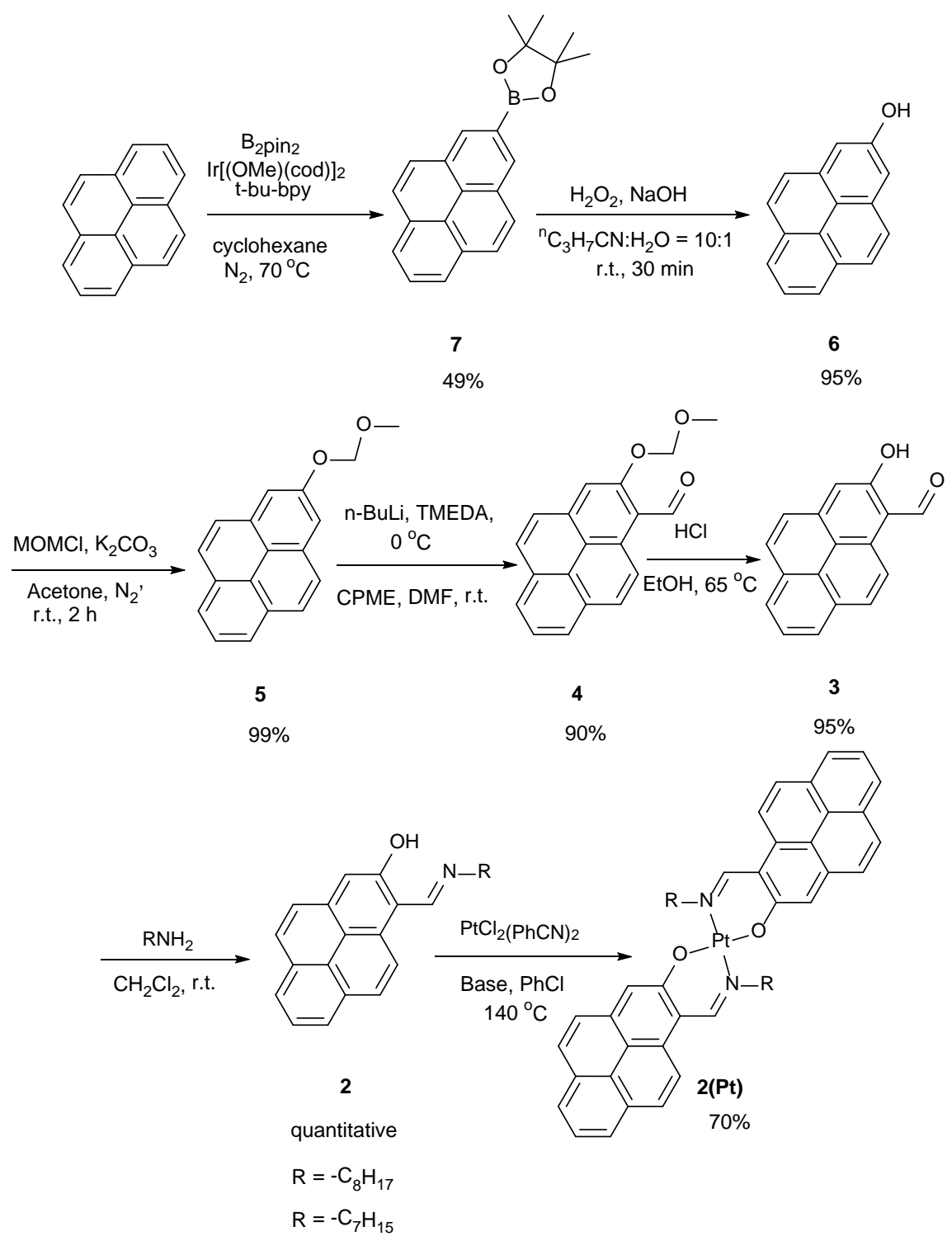

Scheme 1. Syntheses of the ligand 2 and corresponding platinum complex 2(Pt). The small modified alkyl group was performed to obtain single crystals for $\mathrm{X}$-ray crystal analysis. $\mathrm{R}=-\mathrm{C}_{8} \mathrm{H}_{17}$ was replaced with $-\mathrm{C}_{7} \mathrm{H}_{15}$.

The platinum complex $\mathbf{2}(\mathbf{P t})$ was synthesized in a similar metallation method [28] to ligand 2 with $\mathrm{PtCl}_{2}(\mathrm{PhCN})_{2}$ in chlorobenzene and the presence of a base, sodium acetate or sodium propionate, at reflux for $2 \mathrm{~h}$ to give $70 \%$ in yield. Previously, the platinum complex $\mathbf{1}(\mathbf{P t})$ was synthesized in a $80 \%$ yield. Therefore, the metallation reaction of ligand $\mathbf{2}$ had been more difficult than that of ligand $\mathbf{1}$.

\subsection{X-ray Crystal Analysis}

All the spectroscopic data support the formation of the desired platinum complex. Crystallization was attempted for the isomeric complex $2(\mathbf{P t})$ and, fortunately, single crystals suitable for X-ray diffraction analysis were obtained by the slow diffusion of ethylacetate into a solution of $\mathbf{2 ( P t )}$ in chloroform. The molecular structure and selected geometric parameters of $\mathbf{2}(\mathbf{P t})$ were shown in Figure 1 and Table 1, along with the isomer $\mathbf{1}(\mathbf{P t})$.

While the crystal of $1(\mathrm{Pt})$ is made up two crystallographically independent complexes, Complex \#1 and Complex \#2, and the structure of Complex \#1 is represented in Figure 1, the crystal structure of $\mathbf{2 ( P t )}$ is made up of only one type of crystallographical complex. Both platinum complexes $\mathbf{2}(\mathbf{P t})$ and 
$\mathbf{1 ( P t ) ~ h a v e ~ a ~ s q u a r e ~ p l a n a r ~ f o u r ~ c o o r d i n a t i o n ~ g e o m e t r y ~ a n d ~ t h e ~ l i g a n d s ~ c o o r d i n a t e ~ i n ~ a ~ t r a n s ~ m a n n e r , ~}$ which is common in this class of complex. The structure of the complex $\mathbf{2}(\mathbf{P t})$ is more stair-stepped than that of complex $\mathbf{1}(\mathbf{P t})$; the distance between the mean square planes of two pyrene moieties is 0.708 and $0.604 \AA$ for $\mathbf{2}(\mathbf{P t})$ and $\mathbf{1}(\mathbf{P t})^{\# 2}$, respectively. The different interactions between the hydrogen atoms of alkyl group and the oxygen atoms of the confront ligand are 2.269 and 2.351 (2.386) $\AA$ for 2(Pt) and $\mathbf{1}(\mathbf{P t})$, respectively, and the interaction between the nitrogen atom and the oxygen atom of the confront ligand is 2.723 and $2.772(2.787) \AA$ for $\mathbf{2}(\mathbf{P t})$ and $\mathbf{1}(\mathbf{P t})$. Furthermore, we emphasize the difference in bond distance for the oxygen-platinum coordination bond. A bond distance of $1.953 \AA$ was observed for the compound $\mathbf{2}(\mathbf{P t})$, and this distance is shorter than that of the isomer $\mathbf{1}(\mathbf{P t})$, considering the standard deviation of the measurement.

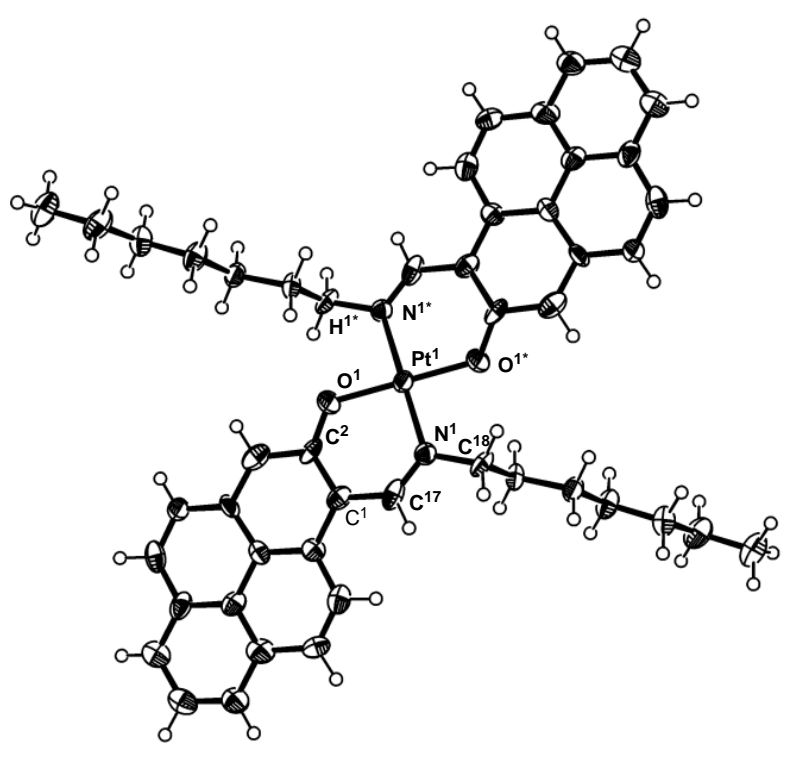

(a)

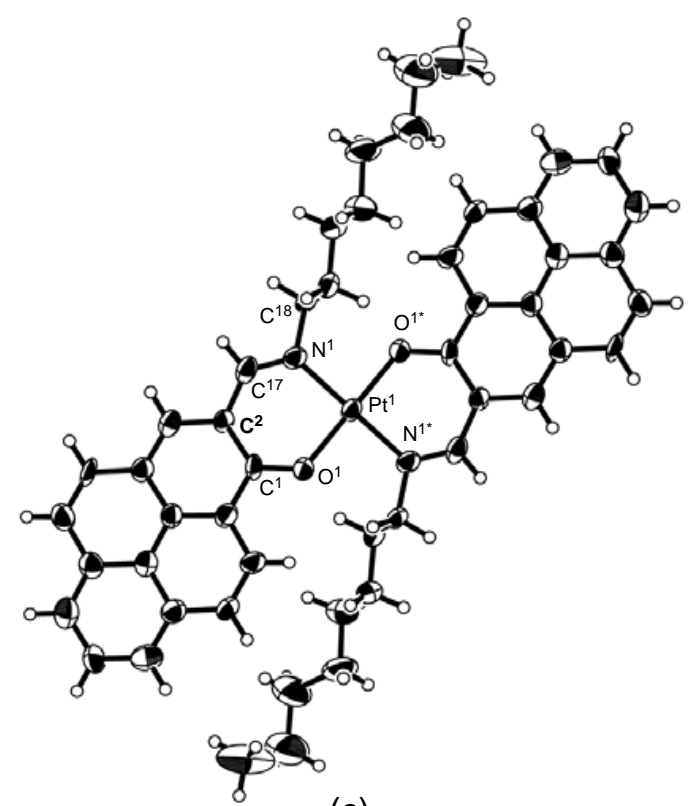

(c)

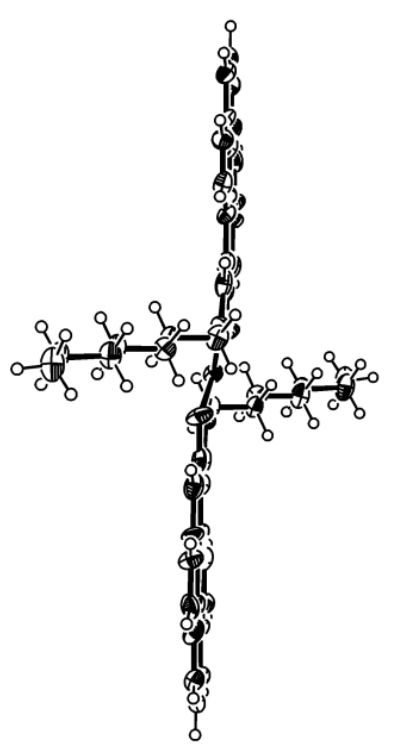

(b)

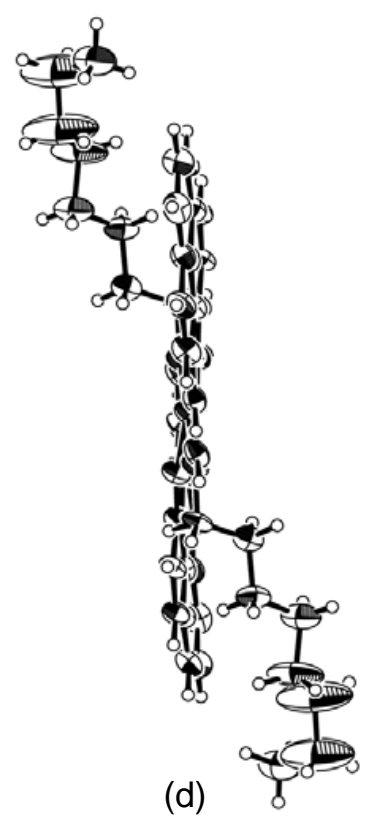

(d)

Figure 1. Molecular structures of 2(Pt) and 1(Pt): (a) top view of 2(Pt); (b) side view of 2(Pt); (c) top view of $\mathbf{1}(\mathbf{P t})$; (d) side view of $\mathbf{1}(\mathbf{P t})$. The thermal ellipsoids are scaled to a $50 \%$ probability level. 
Table 1. Comparison of the selected geometric parameters from the X-ray diffraction analysis and DFT calculations $\left(\mathrm{R}=\mathrm{CH}_{3}\right)$ for the complexes $\mathbf{2}(\mathbf{P t})$ and $\mathbf{1}(\mathbf{P t})$.

\begin{tabular}{|c|c|c|c|c|c|c|}
\hline \multicolumn{3}{|c|}{$2(P t)\left(R={ }^{n} C_{7} H_{15}\right)$} & & \multicolumn{3}{|c|}{$1(P t)\left(R={ }^{n} C_{8} H_{17}\right)$} \\
\hline \multirow{2}{*}{ Parameters } & \multirow{2}{*}{ X-ray } & \multirow{2}{*}{$\begin{array}{l}\text { Optimized } \\
\text { Geometry }\end{array}$} & \multirow{2}{*}{ Parameters } & \multicolumn{2}{|c|}{ X-ray } & \multirow{2}{*}{$\begin{array}{l}\text { Optimized } \\
\text { Geometry }\end{array}$} \\
\hline & & & & $\# 1$ & $\# 2$ & \\
\hline N1-Pt1 & $2.000(7)$ & 2.028 & N1-Pt1 & $2.008(8)$ & $2.014(8)$ & 2.036 \\
\hline $\mathrm{N} 1^{\mathrm{i}}-\mathrm{Pt} 1$ & $2.000(7)$ & 2.028 & $\mathrm{~N} 11^{\mathrm{i}}-\mathrm{Pt} 1$ & $2.008(8)$ & $2.014(8)$ & 2.036 \\
\hline O1-Pt1 & $1.953(6)$ & 2.011 & O1-Pt1 & $1.996(6)$ & $1.991(7)$ & 2.020 \\
\hline O1 $1^{\mathrm{i}}-\mathrm{Pt} 1$ & $1.953(6)$ & 2.011 & $\mathrm{O} 1^{\mathrm{i}}-\mathrm{Pt} 1$ & $1.996(6)$ & $1.991(7)$ & 2.020 \\
\hline O1-C2 & $1.307(13)$ & 1.308 & O1-C1 & $1.291(10)$ & $1.292(10)$ & 1.306 \\
\hline C1-C2 & $1.418(11)$ & 1.434 & C1-C2 & $1.430(12)$ & $1.394(13)$ & 1.429 \\
\hline N1-C18 & $1.482(11)$ & 1.466 & N1-C18 & $1.479(11)$ & $1.479(11)$ & 1.466 \\
\hline N1-C17 & $1.294(12)$ & 1.303 & N1-C17 & $1.295(11)$ & $1.295(11)$ & 1.299 \\
\hline $\mathrm{N} 1-\mathrm{O} 1^{*}$ & 2.723 & 2.826 & $\mathrm{~N} 1-\mathrm{O} 1^{*}$ & 2.772 & 2.787 & 2.812 \\
\hline $\mathrm{O} 1-\mathrm{H} 1^{*}$ & 2.269 & 2.495 & O1-H1* & 2.351 & 2.386 & 2.560 \\
\hline $\mathrm{O} 1^{*}-\mathrm{Pt} 1-\mathrm{N} 1^{*}$ & $93.0(3)$ & 91.216 & $\mathrm{O} 1^{*}-\mathrm{Pt} 1-\mathrm{N} 1^{*}$ & $92.4(3)$ & $91.8(3)$ & 92.20 \\
\hline O1-Pt1-N1 & $93.0(3)$ & 91.216 & O1-Pt1-N1 & $92.4(3)$ & $91.8(3)$ & 92.20 \\
\hline $\mathrm{O} 1^{*}-\mathrm{Pt} 1-\mathrm{N} 1$ & $87.0(3)$ & 88.78 & $\mathrm{O} 1^{*}-\mathrm{Pt} 1-\mathrm{N} 1$ & $87.6(3)$ & 88.2(3) & 87.80 \\
\hline N1-Pt1-N1* & $87.0(3)$ & 88.78 & N1-Pt1-N1* & $87.6(3)$ & 88.2(3) & 87.80 \\
\hline
\end{tabular}

\subsection{IR and ${ }^{1} H$ NMR Spectra}

Dissimilarities between the two isomeric platinum complexes were observed in spectroscopic studies. The vibration spectra of $\mathbf{2}(\mathbf{P t})$ and $\mathbf{1}(\mathbf{P t})$ were completely different in the $4000 \sim 400 \mathrm{~cm}^{-1}$ range. For such complexes, the imine $C=N$ stretching mode $\left(v_{C=N}\right)$ gives the most important absorption $[28,29]$. The frequency of this band is known to be dependent on the coordination position [43]. The bands were observed at 1602 and $1615 \mathrm{~cm}^{-1}$ for $\mathbf{2 ( P t )}$ and $\mathbf{1}(\mathbf{P t})$ [28], respectively. Other characteristic absorptions such as $v_{\mathrm{C}-\mathrm{O}(\text { phenolic) }}$ and the pyrene $\mathrm{C}-\mathrm{H}$ out of plane mode $\left(\gamma_{\mathrm{C}-\mathrm{H}(\text { pyrene) }}\right)$ for $\mathbf{2}(\mathbf{P t})$ and $\mathbf{1}(\mathbf{P t})$ were different as well (see Supplementary Materials).

Similarly, the H-NMR spectra of 2(Pt) and $\mathbf{1}(\mathbf{P t})$ were different from one another (see Supplementary Materials). The signal attributable to imine hydrogen, $\mathrm{H}^{11}$ (in the formula shown in Supplementary Materials), was shifted to a lower field region in $\mathbf{2}(\mathbf{P t})-9.06$ and $8.43 \mathrm{ppm}$ for $\mathbf{2}(\mathbf{P t})$ and $\mathbf{1}(\mathbf{P t})$, respectively. The signal of the pyrene-nucleus hydrogen close to the metal, $\mathrm{H}^{3}$, shows the opposite upfield-shift behavior-7.58 and $8.02 \mathrm{ppm}$ for $\mathbf{2}(\mathbf{P t})$ and $\mathbf{1}(\mathbf{P t})$, respectively. The octyl-group also showed upfield-shift behavior for $\mathrm{H}^{12}-4.22$ and $4.36 \mathrm{ppm}$ for $\mathbf{2}(\mathbf{P t})$ and $\mathbf{1}(\mathbf{P t})$, respectively. This upper field shift is caused by the electropositive $\mathrm{Pt}$, which gives a shielding effect through the inductive effect [28,29]. Therefore, by increasing the distance from the metal, there will be less upper field shift observed (see Supplementary Materials).

\subsection{Photophysical Study}

The absorption and emission spectra of the ligands $\mathbf{2}$ and $\mathbf{1}$ and their corresponding platinum complexes 2(Pt) and $\mathbf{1}(\mathbf{P t})$ are shown in Figure 2. Their photophysical properties, such as their absorption and emission maxima wavelengths ( $\lambda_{\mathrm{abs}}$ and $\lambda_{\mathrm{em}}$, respectively), molar extinction coefficient $\left(\varepsilon_{\mathrm{max}}\right)$, fluorescene quantum yields ( $\phi_{\mathrm{f}}$, for ligands), phosphorescence quantum yields ( $\phi_{\mathrm{p}}$, for complexes), and fluorescence lifetimes ( $\tau_{f}$, for ligands and phosphorescence lifetime $\left(\tau_{p}\right.$, for complexes)), are listed in Table 2.

An interesting observation is the red-shift in the absorption spectra of complexes $\mathbf{2}(\mathbf{P t})$ and $\mathbf{1}(\mathbf{P t})$ (103 and $90 \mathrm{~nm}$, respectively), which is well aligned with that of the corresponding ligands 2 and $\mathbf{1}$. These large shifts suggest that the $\pi$-conjugation was enhanced due to the bidentate complexation of the ligand to the $\mathrm{d}^{8}$ spectroscopically inactive $\mathrm{Pt}^{2+}$ cation. As the bidentate coordination restricts the rotation around the $\mathrm{C} 1-\mathrm{C} 17$ bond and $\mathrm{C} 2-\mathrm{C} 17$ bond, it causes the imino-hydroxypyrene backbone to be in a planar conformation for both $\mathbf{2}(\mathbf{P t})$ and $\mathbf{1}(\mathbf{P t})$. Moreover, an intensity-borrowing phenomenon was observed when considering the transition intensities of both complexes. 

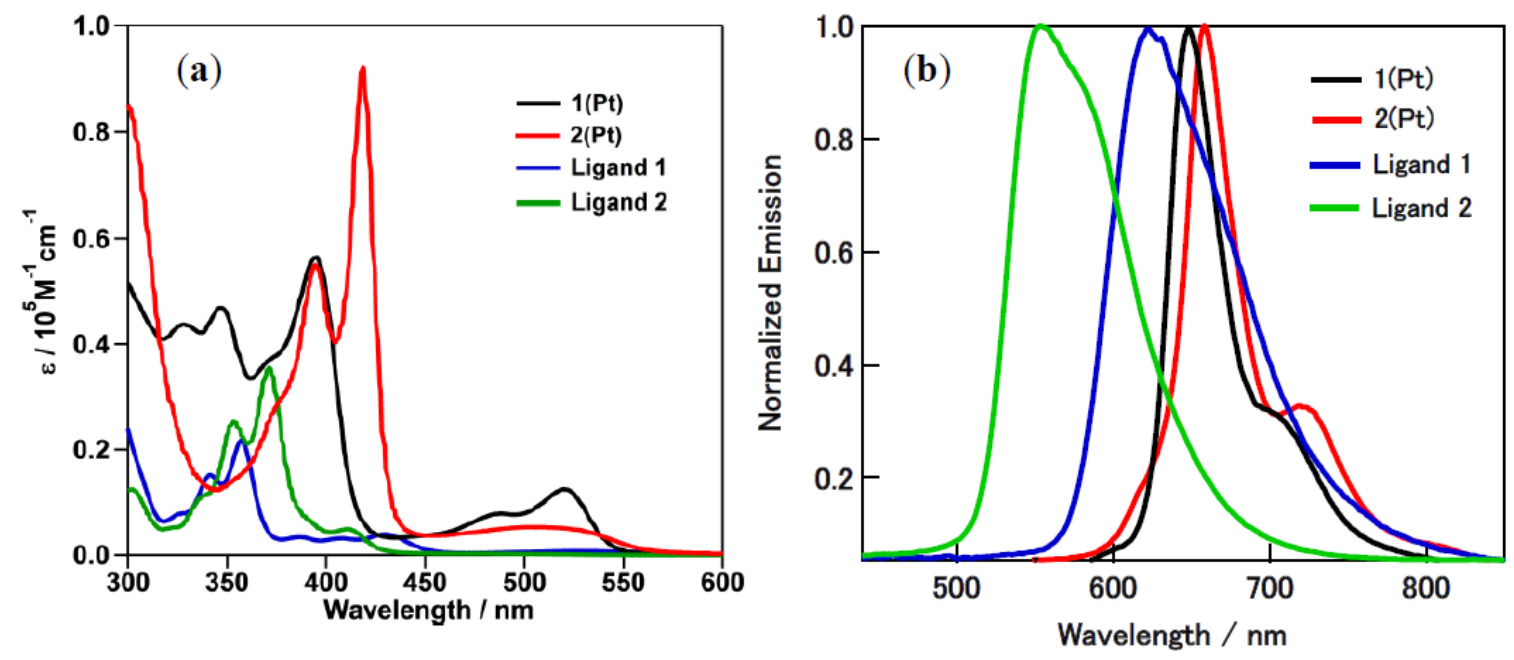

Figure 2. Absorption spectra (a) and fluorescence and phosphorescene spectra (b) of ligands 2 and 1 and complexes $\mathbf{2}(\mathbf{P t})$ and $\mathbf{1}(\mathbf{P t})$ (for each compound, obtained by exciting at their absorption maximum wavelength) in $\mathrm{CH}_{2} \mathrm{Cl}_{2}$ at $25^{\circ} \mathrm{C}$.

Table 2. Photophysical parameters of the platinum complexes $\mathbf{2}(\mathbf{P t})$ and $\mathbf{1}(\mathbf{P t})$ and of their corresponding neutral ligands 1 and 2 in $\mathrm{CH}_{2} \mathrm{Cl}_{2}$ at $25^{\circ} \mathrm{C}$.

\begin{tabular}{cccccc}
\hline Compounds & $\boldsymbol{\lambda}_{\text {abs }}(\mathbf{n m})$ & $\varepsilon_{\max }\left(\mathbf{M}^{-\mathbf{1}} \mathbf{c m}^{-\mathbf{1}}\right)$ & $\boldsymbol{\lambda}_{\text {em }}(\mathbf{n m})$ & $\boldsymbol{\Phi}(\mathbf{\%})$ & $\tau(\mathbf{n s})$ \\
\hline $\mathbf{1}$ & 430 & 3900 & 622 & 8.2 & 0.21 \\
\hline $\mathbf{2}$ & 411 & 4925 & 553 & 6.4 & 0.66 \\
\hline $\mathbf{1 ( P t )}$ & 520 & 11,900 & 648 & 1.0 & 130 \\
\hline $\mathbf{2 ( P t )}$ & 514 & 5164 & 659 & 1.3 & 530 \\
\hline
\end{tabular}

The phosphorescene spectra of complexes $\mathbf{2}(\mathbf{P t})$ and $\mathbf{1}(\mathbf{P t})$ show redshifts (106 and $26 \mathrm{~nm}$, respectively) relative to ligands $\mathbf{2}$ and $\mathbf{1}$ similar to what we observed in the absorption spectra. Both of these redshifts observed in the absorption spectra and phosphorescene spectra can be attributed to the highly resonant $\pi$-conjugated framework of the deprotonated imino-hydroxylpyrene ligand, as it lowers the $\pi^{*}-\pi$ energy gap in the ligand molecular orbitals [44].

The most interesting point is that the phosphorescence lifetime of the isomeric platinum complex $\mathbf{2}(\mathbf{P t})$ is much longer than that of the complex $\mathbf{1}(\mathbf{P t})-0.53$ and $0.13 \mu$ s for $\mathbf{2}(\mathbf{P t})$ and $\mathbf{1}(\mathbf{P t})$, respectively. Meanwhile, the phosphorescence quantum yield of complex 2(Pt) is slightly larger than that of complex $\mathbf{1}(\mathbf{P t})-1.3 \%$ and $1.0 \%$ for $\mathbf{2}(\mathbf{P t})$ and $\mathbf{1}(\mathbf{P t})$, respectively. These can be explained by the differences in their structures and the effect of the nodal plane of pyrene.

\subsection{Electrochemical Properties}

To estimate the HOMO-LUMO gap induced by the changing of the coordinating group on pyrene, electrochemical studies were carried out. Cyclic voltammetry $(\mathrm{CV})$ of the two complexes was carried out in the dry $0.1 \mathrm{M} \mathrm{PhCN}\left[\mathrm{n}-\mathrm{Bu}_{4} \mathrm{~N}_{\mathrm{PF}} \mathrm{PF}_{6}\right.$ supporting electrolyte, with $\mathrm{Fc} / \mathrm{Fc}^{+}$as the reference redox (see general experimental section). The recorded voltammogram is shown in Figure 3 for the range in which all the redox reactions occurred.

Both the isomers $\mathbf{2}(\mathbf{P t})$ and $\mathbf{1}(\mathbf{P t})$ exhibit irreversible first oxidation waves. The first oxidation wave of $\mathbf{2}(\mathbf{P t})(0.35 \mathrm{~V})$ is shifted positively by $0.11 \mathrm{~V}$ compared to that of $\mathbf{1}(\mathbf{P t})(0.24 \mathrm{~V})$, which indicates that the HOMO level of $\mathbf{2}(\mathbf{P t})$ lies lower than that of $\mathbf{1}(\mathbf{P t})$, assuming that the relaxation and electron correlation effects are of the same level in both complexes. In other words, the nodal plane of pyrene decreases the energy level of the HOMO of the complex $\mathbf{2}(\mathbf{P t})$, which contributes in part to the 
hypsochromic-shifted absorption (see absorption spectra). No reduction waves were observed under this measurement condition.

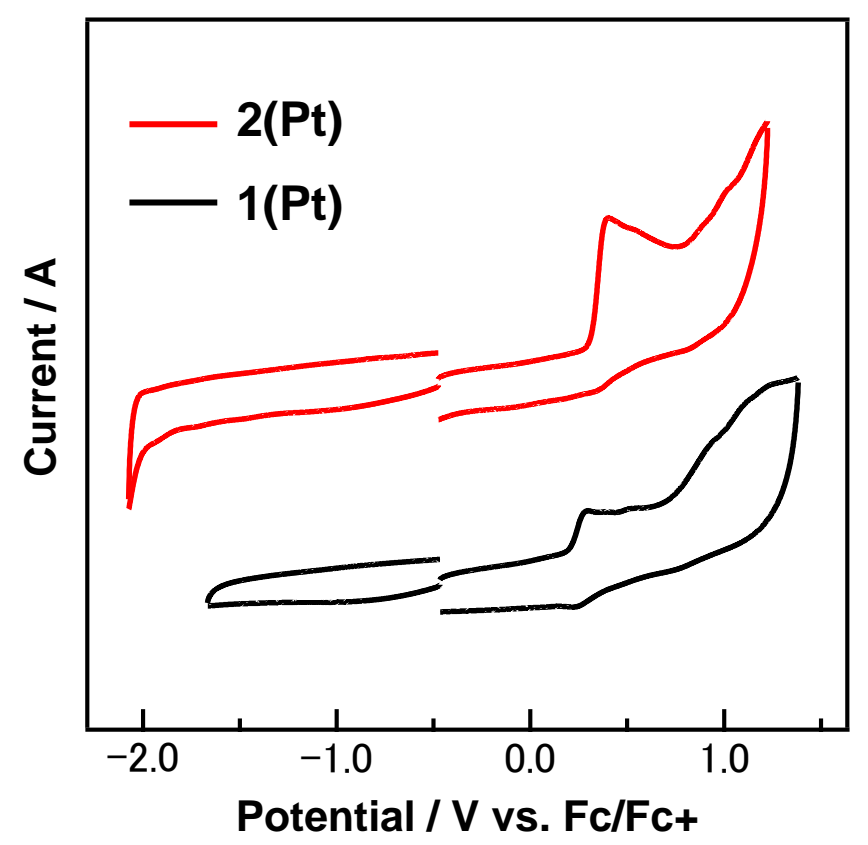

Figure 3. Room temperature cyclic voltammograms of $\mathbf{2}(\mathbf{P t})$ and $\mathbf{1}(\mathbf{P t})$ in Ar-saturated $0.1 \mathrm{M}\left[\mathrm{n}-\mathrm{Bu}_{4} \mathrm{~N}\right] \mathrm{PF}_{6}$ $\mathrm{PhCN}$ sochartlution at a scan rate of $0.10 \mathrm{~V} \mathrm{~s}^{-1}$ with all platinum electrodes.

\subsection{Molecular Orbital Calculations}

Theoretical studies were carried out to obtain further understanding of $\mathbf{1 ( P t )}$ and $\mathbf{2 ( P t )}$. The DFT calculations using Gaussian 09 were performed with density functional theory, B3LYP, using the basic set 6-31G(d) for N, O, H, and C atoms and the basic set LanL2DZ for the Pt atom. All of the geometries were optimized, and the calculated distance and angles for the complexes $\mathbf{2}(\mathbf{P t})$ and $\mathbf{1}(\mathbf{P t})$ were well in agreement with the actual values obtained from the single crystal X-ray diffraction study (see Table 1).

As seen in Figure 4, the frontier molecular orbitals of these platinum complexes are mainly dominated by atomic orbitals originating from ligands in both cases and the contribution of platinum ions is small. The energy levels of the Kohn-Sham frontier orbitals are shown in Figure 4. The shape and energy levels of each frontier orbital of $\mathbf{2}(\mathbf{P t})$ are different from those of $\mathbf{1}(\mathbf{P t})$-i.e., the size of each atomic coefficient (see Figures 4 and 5). It should be emphasized that the most important phenomena attributable to isomerism should be the drastic changes in the energy levels of the orbitals. From Figure 5, the frontier orbitals of ligand 2 are stabilized than those of ligand 1. This property reflects how the metal ligand bondings induce the HOMOs of both the complexes that contain the antibonding $\pi$-interaction between platinum and oxygen. Furthermore, a significant difference was observed for $144 \mathrm{ag}$ of HOMO: -4.89 and $-4.69 \mathrm{eV}$ for $\mathbf{2 ( P t )}$ and $\mathbf{1 ( P t )}$, respectively. Therefore, the energy level of the HOMO of complex 2(Pt) is more stabilized than that of complex $\mathbf{1}(\mathbf{P t})$. This molecular orbital characteristic well explains the higher first oxidation potential in the cyclic voltammogram and blue-shift in the absorption spectroscopy of $\mathbf{2 ( P t )}$ compared to those of $\mathbf{1}(\mathbf{P t})$.

The lowest excitation found in $\mathbf{2}(\mathbf{P t})$ was assigned to be the HOMO to LUMO transition, Au. The absorption spectrum was assigned by time-dependent density functional theory (TDFT) and has been summarized in Table 3. 

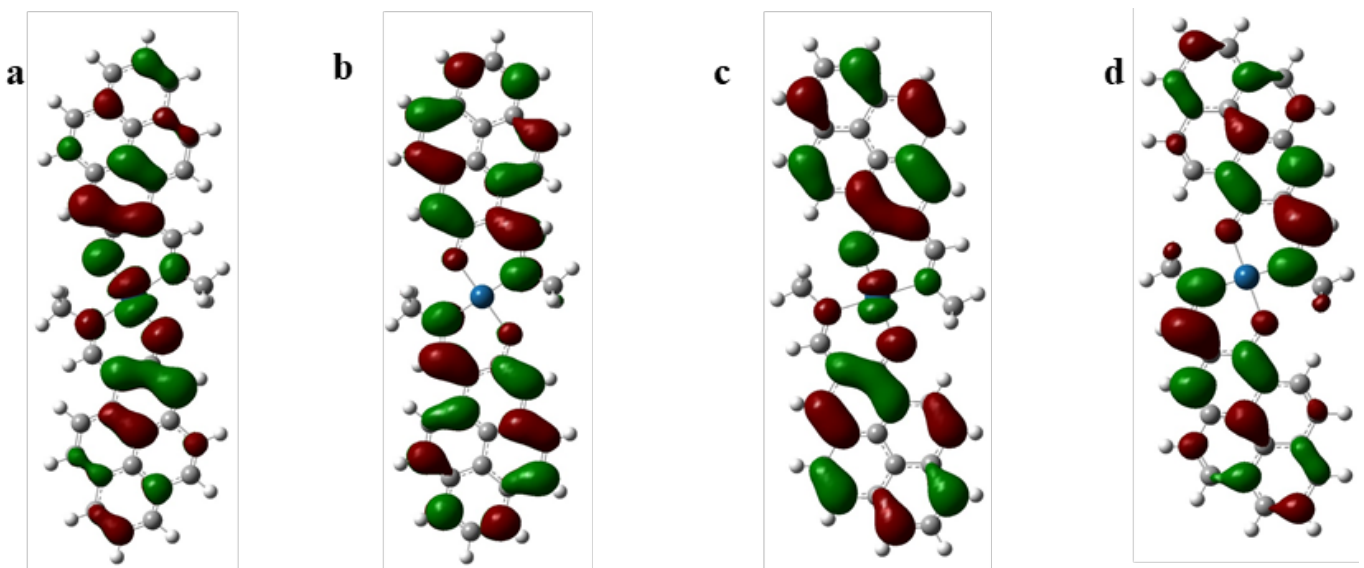

Figure 4. Plots of the (a) HOMO of 2(Pt), (b) LUMO of 2(Pt), (c) HOMO of $\mathbf{1}(\mathbf{P t})$, and (d) LUMO of 1(Pt) obtained from the RB3LYP/6-31g(d) level for C, H, O, N elements and LanL2DZ for Pt element. All the MO surfaces correspond to an isocontour value (0.02 a.u.).

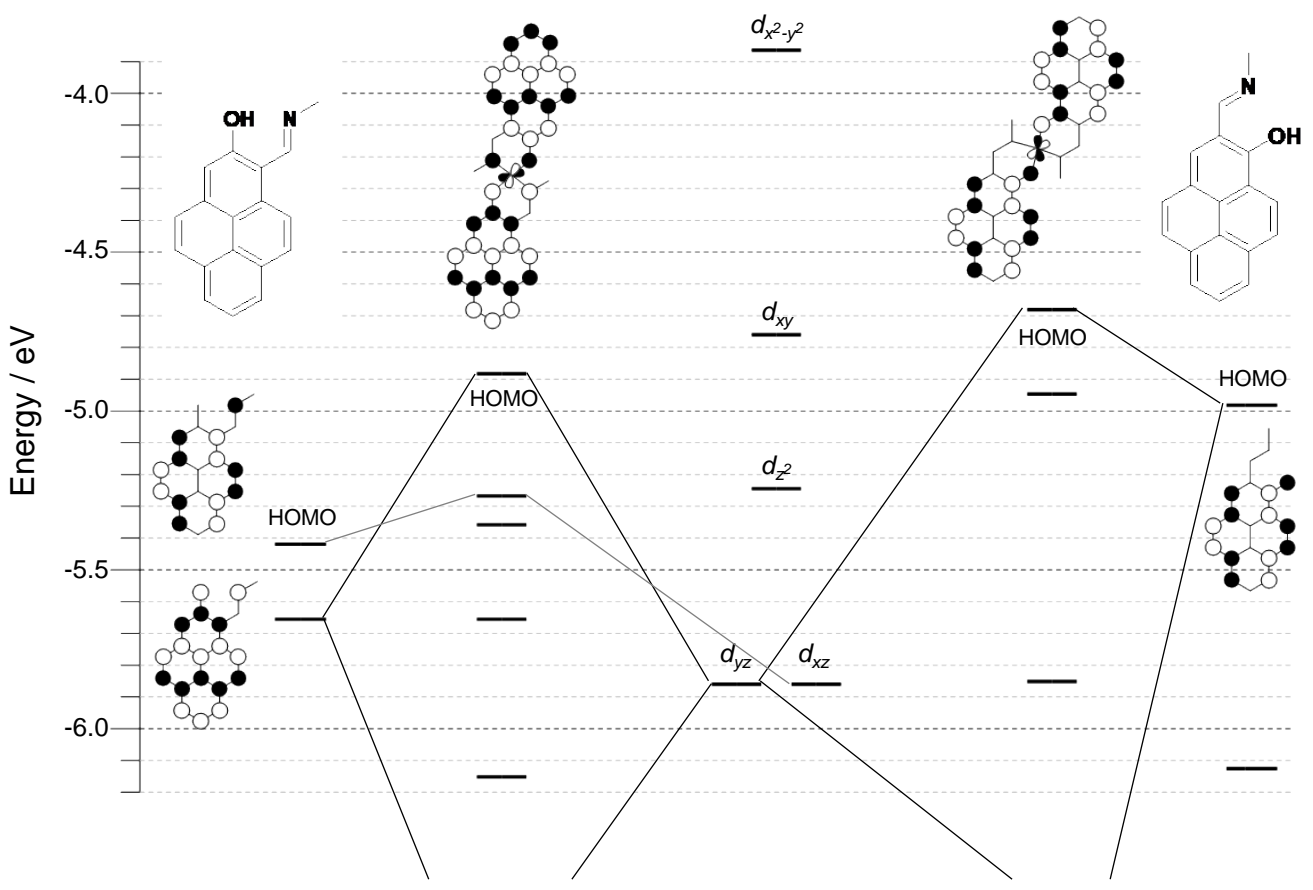

Figure 5. Energy diagrams of the Kohn-Sham orbitals of 2(Pt) and 1(Pt) (B3LYP/LanL2DZ for Pt and 6-31G(d) for other elements) and the shapes of the important orbitals.

Table 3. Composition, energy (eV), calculated and experimental absorption wavelengths (nm), and oscillator strength (OS) of the relevant electronic transitions of ligands $\mathbf{1}$ and 2 and of platinum complexes 2(Pt) and $\mathbf{1}(\mathbf{P t})$ in $\mathrm{CH}_{2} \mathrm{Cl}_{2}$ (only transitions with: $\mathrm{OS}>0.01$ and composition $>10 \%$ considered; $\mathrm{H}=\mathrm{HOMO}, \mathrm{L}=\mathrm{LUMO}) .{ }^{\mathrm{a}}$ From Table 2.

\begin{tabular}{cccccc}
\hline State & Main Compositions & $\begin{array}{c}\text { Energy } \\
(\mathbf{e V})\end{array}$ & $\begin{array}{c}\text { Wavelength } \\
(\mathbf{n m})\end{array}$ & $\begin{array}{c}\lambda_{\exp } \\
(\mathbf{n m})\end{array}$ & OS \\
\hline & & Complex 2(Pt) & & & \\
1 & $\mathrm{H} \rightarrow \mathrm{L}(97 \%)$ & 2.34 & 530 & 514 & 0.041 \\
3 & $\mathrm{H}-1 \rightarrow \mathrm{L}(96 \%)$ & 2.84 & 437 & & 1.175 \\
6 & $\mathrm{H}-2 \rightarrow \mathrm{L}+1(92 \%)$ & 3.17 & 391 & & 0.218 \\
8 & $\mathrm{H}-3 \rightarrow \mathrm{L}+1(84 \%)$ & 3.39 & 366 & & 0.355 \\
15 & $\mathrm{H}-6 \rightarrow \mathrm{L}(76 \%)$ & 3.94 & 314 & & 0.115 \\
\hline
\end{tabular}


Table 3. Cont.

\begin{tabular}{|c|c|c|c|c|c|}
\hline State & Main Compositions & $\begin{array}{c}\text { Energy } \\
(\mathrm{eV})\end{array}$ & $\begin{array}{l}\text { Wavelength } \\
(\mathrm{nm})\end{array}$ & $\begin{array}{c}\lambda_{\exp } \\
(\mathrm{nm})^{\mathrm{a}}\end{array}$ & OS \\
\hline \multicolumn{6}{|c|}{ Complex 1(Pt) } \\
\hline 1 & $\mathrm{H} \rightarrow \mathrm{L}(96 \%)$ & 2.42 & 513 & \multirow[t]{5}{*}{520} & 0.104 \\
\hline 4 & $\mathrm{H}-1 \rightarrow \mathrm{L}+1(93 \%)$ & 3.03 & 410 & & 0.171 \\
\hline 5 & $\mathrm{H} \rightarrow \mathrm{L}+2(95 \%)$ & 3.07 & 403 & & 0.589 \\
\hline 9 & $\mathrm{H}-2 \rightarrow \mathrm{L}(58 \%), \mathrm{H}-1 \rightarrow \mathrm{L}+3(29 \%)$ & 3.46 & 358 & & 0.875 \\
\hline 10 & $\mathrm{H}-2 \rightarrow \mathrm{L}(34 \%), \mathrm{H}-1 \rightarrow \mathrm{L}+3(60 \%)$ & 3.51 & 353 & & 0.018 \\
\hline & & Ligand 2 & & & \\
\hline 1 & $\mathrm{H}-1 \rightarrow \mathrm{L}(36 \%), \mathrm{H} \rightarrow \mathrm{L}(57 \%)$ & 3.22 & 385 & \multirow[t]{5}{*}{411} & 0.246 \\
\hline 2 & $\mathrm{H}-1 \rightarrow \mathrm{L}(55 \%), \mathrm{H} \rightarrow \mathrm{L}(38 \%)$ & 3.32 & 373 & & 0.436 \\
\hline 5 & $\mathrm{H} \rightarrow \mathrm{L}+1(78 \%)$ & 4.33 & 287 & & 0.222 \\
\hline 6 & $\mathrm{H}-2 \rightarrow \mathrm{L}(19 \%), \mathrm{H} \rightarrow \mathrm{L}+2(63 \%)$ & 4.38 & 283 & & 0.020 \\
\hline \multirow[t]{2}{*}{7} & $\begin{array}{c}\mathrm{H}-1 \rightarrow \mathrm{L}+1(36 \%), \mathrm{H}-1 \rightarrow \mathrm{L}+2 \\
(18 \%), \mathrm{H} \rightarrow \mathrm{L}+3(33 \%)\end{array}$ & 4.62 & 268 & & 0.014 \\
\hline & & Ligand 1 & & \multirow{6}{*}{430} & \\
\hline 1 & $\mathrm{H} \rightarrow \mathrm{L}(82 \%), \mathrm{H} \rightarrow \mathrm{L}+1(12 \%)$ & 3.07 & 404 & & 0.118 \\
\hline 2 & $\mathrm{H} \rightarrow \mathrm{L}(11 \%), \mathrm{H} \rightarrow \mathrm{L}+1(79 \%)$ & 3.49 & 355 & & 0.276 \\
\hline 4 & $\mathrm{H}-1 \rightarrow \mathrm{L}(48 \%), \mathrm{H}-1 \rightarrow \mathrm{L}+1(31 \%)$ & 4.25 & 292 & & 0.144 \\
\hline 5 & $\mathrm{H}-1 \rightarrow \mathrm{L}(39 \%), \mathrm{H}-1 \rightarrow \mathrm{L}+1(46 \%)$ & 4.44 & 279 & & 1.263 \\
\hline 6 & $\mathrm{H}-2 \rightarrow \mathrm{L}(76 \%)$ & 4.67 & 266 & & 0.074 \\
\hline
\end{tabular}

\section{Experimental Section}

\subsection{General Procedures}

General experimental details are already reported in previous reports [28,29,45-47].

\subsection{Synthesis of the Isomeric Platinum Complex}

The preparation of the isomeric platinum complex $\mathbf{1 ( P t )}$ was performed as previously reported [28].

Preparation of 4,4,5,5-Tetramethyl-2-pyren-2-yl-[1,3,2]dioxaborolane [2-(Bpin)-pyrene] (7): In a nitrogen-filled three-neck flask, $[\operatorname{Ir}(\mu-\mathrm{OMe})(\mathrm{cod})]_{2}(99.77 \mathrm{mg}, 0.15 \mathrm{mmol}), 4,4$ '-di-tert-butyl-2,2'-dipyridyl $(80.96 \mathrm{mg}, 0.30 \mathrm{mmol})$, and bis(pinacolato)diboron (281 $\mathrm{mg}, 1.11 \mathrm{mmol})$ were dissolved in cyclohexane $(30 \mathrm{~mL})$. To this mixture, pyrene $(1.012 \mathrm{~g}, 5.00 \mathrm{mmol})$ and bis(pinacolato)diboron $(735 \mathrm{mg}, 2.89 \mathrm{mmol})$ were added and the reaction was stirred at $70{ }^{\circ} \mathrm{C}$ for $17 \mathrm{~h}$ under a nitrogen atmosphere. The reaction mixture was passed through a silica plug (eluent: $\mathrm{CH}_{2} \mathrm{Cl}_{2}$ ) and the solvent was removed under reduced pressure. The purification of the residue by silica gel column chromatography (eluent: hexane/ $\mathrm{CH}_{2} \mathrm{Cl}_{2}$ 1:1) obtained 7 (788 mg, 49\% using NMR for weight calculation), unreacted pyrene (332 mg, 33\%), and pyrene-2,7-bis(4,4,5,5-tetramethyl-[1,3,2]dioxaborolane) (133 mg using NMR for weight calculation). To get a purer product, subsequent recrystallization from hexane was performed to give 7 as a white solid.

${ }^{1} \mathrm{H}$ NMR (500 MHz, $\left.\mathrm{CDCl}_{3}\right): \delta=8.64(\mathrm{~s}, 2 \mathrm{H}), 8.17(\mathrm{~d}, J=7.6 \mathrm{~Hz}, 2 \mathrm{H}), 8.11(\mathrm{~d}, J=8.9 \mathrm{~Hz}, 2 \mathrm{H})$, $8.06(\mathrm{~d}, J=8.9 \mathrm{~Hz}, 2 \mathrm{H}) ; 8.01(\mathrm{t}, J=7.6 \mathrm{~Hz}, 1 \mathrm{H}), 1.46 \mathrm{ppm}(\mathrm{s}, 12 \mathrm{H})$.

Preparation of 2-hydroxypyrene (6): Compound 7 (125 mg, $0.38 \mathrm{mmol})$ and $\mathrm{NaOH}(47 \mathrm{mg}$, $1.18 \mathrm{mmol}$ ) were dissolved in n-butyronitrile $(8 \mathrm{~mL})$. To this mixture, an aqueous solution of $\mathrm{H}_{2} \mathrm{O}_{2}$ (134 mg, $1.18 \mathrm{mmol}, 30 \%)$ and $0.8 \mathrm{~mL}$ of water was added. After being stirred at room temperature for $30 \mathrm{~min}$, the solution was acidified to $\mathrm{pH} 1-2$ using $1 \mathrm{M} \mathrm{HCl}$. The product was diluted with water $(15 \mathrm{~mL})$ and extracted with $\mathrm{CHCl}_{3}$ with $(3 \times 15 \mathrm{~mL})$. The combined organic phases were washed with water $(30 \mathrm{~mL})$ and brine $(15 \mathrm{~mL})$, dried over $\mathrm{MgSO}_{4}$, and the solvent was removed under a reduced pressure. The residue was washed with hexane $(3 \times 3 \mathrm{~mL})$ to obtain $6(79 \mathrm{mg}, 95 \%)$ as a light-brown solid.

${ }^{1} \mathrm{H} \mathrm{NMR}\left(500 \mathrm{MHz}, \mathrm{CDCl}_{3}\right): \delta=8.16(\mathrm{~d}, J=7.6 \mathrm{~Hz}, 2 \mathrm{H}), 8.06(\mathrm{~d}, J=9.0 \mathrm{~Hz}, 2 \mathrm{H}), 7.98-7.91(\mathrm{~m}, 3 \mathrm{H})$, 7.64 (s, $2 \mathrm{H}), 5.17$ (s, $1 \mathrm{H})$. 
Preparation of 2-Methoxymethoxypyrene (5). To a stirring solution of 2-hydroxypyrene (208 $\mathrm{mg}$, $0.953 \mathrm{mmol})$ and $\mathrm{K}_{2} \mathrm{CO}_{3}(666 \mathrm{mg}, 4.82 \mathrm{mmol})$ in acetone $(10 \mathrm{~mL})$ at $0{ }^{\circ} \mathrm{C}$ under nitrogen, chloromethyl methyl ether $(100 \mu \mathrm{L}, 1.31 \mathrm{mmol})$ was added and the reaction was stirred at room temperature for $90 \mathrm{~min}$. Additional chloromethyl methyl ether $(20 \mu \mathrm{L}, 0.26 \mathrm{mmol})$ was added and the reaction was stirred for another $90 \mathrm{~min}$. The product was diluted with water and extracted with $\mathrm{CHCl}_{3}$. The combined organic phases were washed with water and brine, dried over $\mathrm{MgSO}_{4}$, and the solvent was removed under a reduced pressure. The crude material was purified by chromatography over silica gel eluting with 1:1 hexane: $\mathrm{CH}_{2} \mathrm{Cl}_{2}$ to yield the pure product 5 ( $248 \mathrm{mg}$, $99 \%$ ) as a pale yellow solid. To get a purer sample, the product was recrystallized with hexane. $\mathrm{R}_{\mathrm{f}}=0.27$ (hexane/ dichloromethane) $=1: 1$ as eluent).

M.p. $89-90^{\circ} \mathrm{C} ;{ }^{1} \mathrm{H} \mathrm{NMR}\left(500 \mathrm{MHz}, \mathrm{CDCl}_{3}\right): \delta=8.15(\mathrm{~d}, J=7.6 \mathrm{~Hz}, 2 \mathrm{H}), 8.05(\mathrm{~d}, J=9.0 \mathrm{~Hz}, 2 \mathrm{H})$, $7.99(\mathrm{~d}, J=9.0 \mathrm{~Hz}, 2 \mathrm{H}), 7.94(\mathrm{t}, J=7.6 \mathrm{~Hz}, 1 \mathrm{H}), 7.86(\mathrm{~s}, 2 \mathrm{H}), 5.46(\mathrm{~s}, 2 \mathrm{H}), 3.60(\mathrm{~s}, 3 \mathrm{H}) ;{ }^{13} \mathrm{C} \mathrm{NMR}$ $\left(500 \mathrm{MHz}, \mathrm{CDCl}_{3}\right) \delta=155.4,132.6,130.3,128.1,126.9,125.2,125.1,124.6,120.7,112.6,95.0,56.2 ; \mathrm{IR}(\mathrm{KBr})$ : 3038, 2911, 2826, 1639, 1628, 1600, 1481, 1450, 1406, 1319, 1283, 1213, 1155, 1135, 1082, 1073, 998, 976, 958, 932, 914, 867, 855, 838, 813, 756, 705, 637, 613, 562, 551, 500, 419; MS (APCI): Calcd. for $\mathrm{C}_{17} \mathrm{H}_{10} \mathrm{O}_{2}$ $\left(\mathrm{M}^{+}\right)$: 262; Found: 262; Anal. Calcd for $\mathrm{C}_{18} \mathrm{H}_{14} \mathrm{O}_{2}$ : C 82.42, H 5.38; found: C 82.61, H 5.37.

Preparation of 2-Methoxymethoxy-1-pyrenecarbaldehyde (4): To a stirring solution of 5 (180 mg, $0.686 \mathrm{mmol})$ and distilled $N, N, N^{\prime}, N^{\prime}$-tetramethylethylenediamine $(0.160 \mathrm{~mL}, 1.07 \mathrm{mmol})$ in dry cyclopentyl methyl ether $(9 \mathrm{~mL})$ cooled to $0{ }^{\circ} \mathrm{C}$ under nitrogen, $n$-butyllithium $(0.7 \mathrm{~mL}$ of $1.6 \mathrm{M}$ in hexane solution, $1.11 \mathrm{mmol})$ was added and the reaction was stirred for $1 \mathrm{~h}$. Dry DMF $(0.140 \mathrm{~mL}$, $1.807 \mathrm{mmol}$ ) was added and the reaction was allowed to warm to room temperature with stirring over $1 \mathrm{~h}$ before being quenched with a dilute $\mathrm{NH}_{4} \mathrm{Cl}$ aqueous solution. The mixture was diluted with EtOAc, washed with water and brine, dried over $\mathrm{MgSO}_{4}$, and the solvent was removed under a reduced pressure. The crude material was purified by chromatography over silica gel eluting with 40:1 $\mathrm{CH}_{2} \mathrm{Cl}_{2}$ :EtOAc to afford the pure product $4(196 \mathrm{mg}$, 98\%) as a yellow solid. To get a purer sample, the product was recrystallized with ethyl acetate to give $151.4 \mathrm{mg}(76 \%) . R_{\mathrm{f}}=0.33$ (chloroform as eluent).

M.p. $158{ }^{\circ} \mathrm{C} ;{ }^{1} \mathrm{H}$ NMR $\left(500 \mathrm{MHz}, \mathrm{CDCl}_{3}\right): \delta=11.14(\mathrm{~s}, 1 \mathrm{H}), 9.53(\mathrm{~d}, J=9.5 \mathrm{~Hz}, 1 \mathrm{H}), 8.28-8.20$ $(\mathrm{m}, 3 \mathrm{H}), 8.14(\mathrm{~d}, J=8.9 \mathrm{~Hz}, 1 \mathrm{H}), 8.00(\mathrm{t}, \mathrm{J}=7.6 \mathrm{~Hz}, 1 \mathrm{H}), 7.96(\mathrm{~d}, J=8.9 \mathrm{~Hz}, 1 \mathrm{H}), 7.92(\mathrm{~s}, 1 \mathrm{H})$, 5.55 (s, $2 \mathrm{H}), 3.63(\mathrm{~s}, 3 \mathrm{H}) ;{ }^{13} \mathrm{C} \mathrm{NMR}\left(500 \mathrm{MHz}, \mathrm{CDCl}_{3}\right) \delta=192.7,159.3,137.2,131.8,131.6,131.0,130.2$, 129.8, 127.2, 126.9, 126.8, 125.8, 124.3, 123.9, 120.4, 117.3, 110.4, 95.3, 56.7; IR (KBr) 3040, 2997, 2967, 2951, 2914, 2875, 2783, 1664, 1639, 1626, 1595, 1583, 1538, 1499, 1490, 1482, 1471, 1420, 1399, 1382, 1367, 1279, 1246, 1230, 1220, 1187, 1165, 1154, 1132, 1113, 1099, 1067, 1029, 991, 937, 922, 896, 857, 841, 826, 778, 761, 712, 683, 673, 649, 608, 590, 538, 502, 445, 420; MS(APCI): Calcd. for $\mathrm{C}_{19} \mathrm{H}_{14} \mathrm{O}_{3}\left([\mathrm{M}+\mathrm{H}]^{+}\right): 291$; Found: 291; Anal. Calcd for $\mathrm{C}_{19} \mathrm{H}_{14} \mathrm{O}_{3}$ : C 78.61, H: 4.86; found: C: 78.77, H: 4.81 .

Preparation of 2-Hydroxy-1-pyrenecarbaldehyde (3): To a stirring solution of $4(120 \mathrm{mg}, 0.413 \mathrm{mmol})$ in THF $(20 \mathrm{~mL})$ at room temperature, hydrochloride solution $(0.8 \mathrm{~mL}, 5 \mathrm{M})$ was added and the reaction was heated at $65^{\circ} \mathrm{C}$ for $10 \mathrm{~h}$. The solution was then cooled to room temperature and the solvent was removed and the residue was purified by flash chromatography over silica gel eluting with $\mathrm{CH}_{2} \mathrm{Cl}_{2}$ to afford $108 \mathrm{mg}$ of pure product as a yellow solid (quantitative). To get a purer product, the obtained sample was recrystallized with ethyl acetate. $R_{\mathrm{f}}=0.42$ (chloroform as eluent).

M.p. $180{ }^{\circ} \mathrm{C} ;{ }^{1} \mathrm{H}-\mathrm{NMR}\left(500 \mathrm{MHz}, \mathrm{CDCl}_{3}\right) \delta=12.52(\mathrm{~s}, 1 \mathrm{H}), 11.10(\mathrm{~s}, 1 \mathrm{H}), 8.64(\mathrm{~d}, J=9.3 \mathrm{~Hz}$, $1 \mathrm{H}), 8.24(\mathrm{~d}, J=8.96 \mathrm{~Hz}, 2 \mathrm{H}), 8.19(\mathrm{~d}, J=7.5,1 \mathrm{H}), 8.09(\mathrm{~d}, J=9.0 \mathrm{~Hz}, 1 \mathrm{H}), 7.98(\mathrm{t}, J=7.6 \mathrm{~Hz}, 1 \mathrm{H})$, $7.84(\mathrm{~d}, J=9.0 \mathrm{~Hz}, 1 \mathrm{H}), 7.59(\mathrm{~s}, 1 \mathrm{H}) ;{ }^{13} \mathrm{C}-\mathrm{NMR}\left(500 \mathrm{MHz}, \mathrm{CDCl}_{3}\right) \delta=193.6,161.4,139.2,133.9,132.1$, 131.0, 129.9, 129.3, 127.6, 126.7, 125.6, 124.4, 119.1, 118.6, 113.3, 112.1; IR (KBr) 1635, 1594, 1580, 1536, 1438, 1428, 1406, 1335, 1301, 1278, 1243, 1180, 1145, 1134, 1019, 987, 864, 839, 821, 796, 717, 684, 655, 506, 523, 484, 443; MS(APCI): Calcd. for $\mathrm{C}_{17} \mathrm{H}_{10} \mathrm{O}_{2}\left(\mathrm{M}+\mathrm{H}^{+}\right)$: 247; Found: 247; Anal. Calcd for $\mathrm{C}_{17} \mathrm{H}_{10} \mathrm{O}_{2}$ : C 82.91, H: 4.09; found: C: 82.98, H: 4.07.

Preparation of (E)-2-(n-octylimino)methylpyren-1-ol (2): To a stirring solution of 3 (39 mg, $0.158 \mathrm{mmol})$ in $\mathrm{CH}_{2} \mathrm{Cl}_{2}(4 \mathrm{~mL})$ at room temperature, $\mathrm{n}$-octyl amine $(25.5 \mathrm{mg}, 0.198 \mathrm{mmol})$ was added and the reaction was carried out for $2 \mathrm{~h}$. The solvent was then removed and the residue was purified by 
flash chromatography over silica gel eluting with $50: 1 \mathrm{CHCl}_{3}$ :EtOAc to afford $56 \mathrm{mg}$ of pure product 2 as a yellow solid $(99 \%) . R_{\mathrm{f}}=0.65$ (chloroform/ethyl acetate) $=5: 1$ as eluent).

M.p. $88^{\circ} \mathrm{C},{ }^{1} \mathrm{H}-\mathrm{NMR}\left(500 \mathrm{MHz}, \mathrm{CDCl}_{3}\right) \delta=15.30(\mathrm{~s}, 1 \mathrm{H}), 9.52(\mathrm{~s}, 1 \mathrm{H}), 8.44(\mathrm{~d}, J=9.3 \mathrm{~Hz}, 1 \mathrm{H})$, 8.20-8.10 (m, $3 \mathrm{H}), 8.01(\mathrm{~d}, J=8.8 \mathrm{~Hz}, 1 \mathrm{H}), 7.90(\mathrm{t}, J=7.6 \mathrm{~Hz}, 1 \mathrm{H}), 7.87(\mathrm{~d}, J=9.0 \mathrm{~Hz}, 1 \mathrm{H}), 7.68(\mathrm{~s}, 1 \mathrm{H})$, $3.80(\mathrm{t}, J=6.8 \mathrm{~Hz}, 2 \mathrm{H}), 1.82$ (quintet, $2 \mathrm{H}), 1.48$ (quintet, $2 \mathrm{H}), 1.43-1.23(\mathrm{~m}, 8 \mathrm{H}), 0.88(\mathrm{t}, J=7.2 \mathrm{~Hz}$, $3 \mathrm{H}) ;{ }^{13} \mathrm{C}$ NMR $\left(500 \mathrm{MHz}, \mathrm{CDCl}_{3}\right) \delta=161.5,161.1,135.4,131.4,130.1,129.7,129.3,129.1,126.9,126.3$, 126.1, 124.9, 124.8, 119.8, 118.6, 113.9, 110.9, 59.8, 31.8, 31.1, 29.4, 29.2, 27.3, 22.7, 14.1; IR (KBr) 3043, 2948, 2932, 2924, 2890, 2845, 1620, 1583, 1551, 1543, 1448, 1466, 1355, 1300, 1243, 1178, 1149, 1128, 1089, 1073, 1055, 860, 838, 819, 799, 757, 728, 684, 662, 590, 419; MS (APCI): Calcd. for $\mathrm{C}_{25} \mathrm{H}_{27} \mathrm{NO}\left([\mathrm{M}+\mathrm{H}]^{+}\right.$): 358; Found: 358. Anal. Calcd for $\mathrm{C}_{25} \mathrm{H}_{27} \mathrm{NO}$ : C 83.99, H 7.61, N 3.92. Found: C 83.80, H 7.61, N 3.93; $\lambda_{\max }\left(\mathrm{CH}_{2} \mathrm{Cl}_{2}\right) / \mathrm{nm} 411\left(\varepsilon / \mathrm{dm}^{3} \mathrm{~mol}^{-1} \mathrm{~cm}^{-1} 4,925\right), 372$ (35,435), 354 (25,225), 336 (sh) (10,751).

Preparation of the new $\mathrm{Pt}(\mathrm{II})$ pyrene complex, 2(Pt): The same procedures described for $\mathbf{1}(\mathbf{P t})$ were followed [28].

Procedure A: To a mixture of $2(20 \mathrm{mg}, 0.056 \mathrm{mmol})$ and anhydrous $\mathrm{CH}_{3} \mathrm{COONa}(10.5 \mathrm{mg}$, $0.127 \mathrm{mmol})$ in $4 \mathrm{~mL}$ of $\mathrm{PhCl}, \mathrm{PtCl}_{2}(\mathrm{PhCN})_{2}(12 \mathrm{mg}, 0.025 \mathrm{mmol})$ was added at $140{ }^{\circ} \mathrm{C}$. The mixture was stirred for 2 hours. After being cooled to room temperature, the solvent was removed and the residue was washed with methanol to obtain $2(\mathbf{P t})$ as a red solid. Yield: $14.1 \mathrm{mg}(61 \%) ; R_{\mathrm{f}}=0.41$ (hexane/chloroform $=1: 3$ as eluent).

Procedure B: To a mixture of $2(53 \mathrm{mg}, 0.148 \mathrm{mmol})$ and anhydrous $\mathrm{C}_{2} \mathrm{H}_{5} \mathrm{COONa}(71.6 \mathrm{mg}$, $0.745 \mathrm{mmol})$ in $2 \mathrm{~mL}$ of $\mathrm{PhCl}, \mathrm{PtCl}_{2}(\mathrm{PhCN})_{2}(31.5 \mathrm{mg}, 0.067 \mathrm{mmol})$ was added at $140{ }^{\circ} \mathrm{C}$. The mixture was stirred for 1.5 hours. After being cooled to room temperature, the solvent was removed and the residue was purified by chromatography (hexane/chloroform $=1: 3$ as eluent) to give $\mathbf{2 ( P t )}$ as a red solid. Yield: $42.1 \mathrm{mg}(70 \%)$.

Mp: decomposed at $216{ }^{\circ} \mathrm{C} ;{ }^{1} \mathrm{H}$ NMR $\left(500 \mathrm{MHz}, \mathrm{CDCl}_{3}\right) \delta 9.06(\mathrm{~s}, 2 \mathrm{H}), 8.28(\mathrm{~d}, J=9.4 \mathrm{~Hz}$, $2 \mathrm{H}), 8.20-8.13(\mathrm{~m}, 4 \mathrm{H}), 8.06(\mathrm{~d}, J=7.1 \mathrm{~Hz}, 2 \mathrm{H}), 7.95(\mathrm{~d}, J=9.1 \mathrm{~Hz}, 2 \mathrm{H}), 7.82(\mathrm{t}, J=7.6 \mathrm{~Hz}, 2 \mathrm{H})$, $7.69(\mathrm{~d}, 9.1 \mathrm{~Hz}, 2 \mathrm{H}), 7.58(\mathrm{~s}, 2 \mathrm{H}) ; 4.22(\mathrm{t}, J=7.4 \mathrm{~Hz}, 4 \mathrm{H}), 2.08(\mathrm{~m}, 4 \mathrm{H}), 1.61-1.21(\mathrm{~m}, 16 \mathrm{H}), 0.83(\mathrm{t}, J=7.0$ $\mathrm{Hz}, 6 \mathrm{H}) ;{ }^{13} \mathrm{C}-\mathrm{NMR}\left(500 \mathrm{MHz}, \mathrm{CDCl}_{3}\right) \delta=162.3,153.8,135.7,132.4,130.3,129.6,129.3,128.7,127.1$, 126.1, 125.9, 125.0, 124.7, 120.4, 118.5, 117.1, 114.6, 60.1, 33.0, 31.9, 29.5, 29.4, 27.1, 22.6, 14.1; IR (KBr) 3035, 2922, 2851, 1602, 1574, 1527, 1451, 1428, 1405, 1371, 1295, 1217, 1191, 1179, 1153, 1135, 1091, 861, 834, 812, 774, 755, 683, 672, 663, 530, 501, 429; MS(APCI): Calcd. for $\mathrm{C}_{50} \mathrm{H}_{52} \mathrm{~N}_{2} \mathrm{O}_{2} \mathrm{Pt}\left([\mathrm{M}+\mathrm{H}]^{+}\right)$: 908; Found: 908. Anal. Calcd for $\mathrm{C}_{50} \mathrm{H}_{52} \mathrm{~N}_{2} \mathrm{O}_{2} \mathrm{Pt}$ : C, 66.14; H, 5.77; N, 3.09. Found: $\mathrm{C}, 66.11 ; \mathrm{H}, 6.01 ; \mathrm{N}, 2.94$; $\lambda_{\max }\left(\mathrm{CH}_{2} \mathrm{Cl}_{2}\right) / \mathrm{nm} 514\left(\varepsilon / \mathrm{dm}^{3} \mathrm{~mol}^{-1} \mathrm{~cm}^{-1} 5164\right), 419(90,574), 395(53,934), 375$ (28,293). The single crystals suitable for X-ray crystallography analysis were obtained by the vapor diffusion of a solvent system of $\mathrm{CHCl}_{3} / \mathrm{EtOAc}$.

Details of the crystallization procedures and the important crystallographic parameters can be found in the experimental section and Table 4, while full CIFs are available elsewhere.

Table 4. Crystal data and structure refinement for the platinum complexes $\mathbf{2}(\mathbf{P t})$ and $\mathbf{1}(\mathbf{P t})$.

\begin{tabular}{ccc}
\hline Complex & $\mathbf{2 ( P t )}$ & $\mathbf{1 ( P t )}$ \\
\hline Formula & $\mathrm{C}_{48} \mathrm{H}_{48} \mathrm{~N}_{2} \mathrm{O}_{2} \mathrm{Pt}$ & $\mathrm{C}_{50} \mathrm{H}_{52} \mathrm{~N}_{2} \mathrm{O}_{2} \mathrm{Pt}$ \\
$\mathrm{M}$ & 879.98 & 908.03 \\
Crystal Size/ mm & $0.04 \times 0.03 \times 0.03$ & $0.13 \times 0.08 \times 0.05$ \\
Crystal Color & Red & Red \\
$\lambda / \AA$ & 0.71075 & 0.71075 \\
$\mathrm{~T} / \mathrm{K}$ & 173 & 123 \\
Crystal System & Monoclinic & Triclinic \\
Space Group & $\mathrm{P} 21 / \mathrm{c}$ & $\mathrm{P}-1$ \\
$\mathrm{a} / \AA$ & $4.8015(9)$ & $11.146(4)$ \\
$\mathrm{b} / \AA$ & $14.434(2)$ & $11.495(4)$ \\
$\mathrm{c} / \AA$ & $27.072(5)$ & $17.015(6)$ \\
\hline
\end{tabular}


Table 4. Cont.

\begin{tabular}{ccc}
\hline Complex & $\mathbf{2 ( P t )}$ & $\mathbf{1 ( P t )}$ \\
\hline$\alpha / \mathrm{deg}$ & 90 & $85.512(7)$ \\
$\beta / \mathrm{deg}$ & $93.043(7)$ & $85.047(6)$ \\
$\gamma / \mathrm{deg}$ & 90 & $64.606(5)$ \\
$\mathrm{V} / \AA^{3}$ & $1873.6(6)$ & $1960.0(11)$ \\
$\mathrm{Z}$ & 2 & 2 \\
$\rho / \mathrm{g} \mathrm{cm}^{-1}$ & 1.560 & 1.539 \\
$\mu / \mathrm{mm}^{-1}$ & 3.788 & 3.624 \\
$\theta_{\max } / \mathrm{deg}$ & 27.52 & 27.52 \\
$\mathrm{R}_{1}$ & 0.0500 & 0.0544 \\
$w R_{2}$ & 0.2349 & 0.1170 \\
\hline
\end{tabular}

\section{Conclusions}

With the aim to understand the effect of the nodal plane of pyrene on the properties of metal complexes, we designed and synthesized successfully ligand 2 for a comparison with the previous reported isomeric form 1 . The Pt complex $\mathbf{2}(\mathbf{P t})$ was obtained in a seven-step synthesis and characterized by spectroscopies and diffraction studies. Reflecting the effect of the nodal plane of pyrene, the obtained metal complex shows a slight color and higher oxidation potential. The Pt-O coordination bond distances are different between the two isomeric platinum complexes. The most interesting point is that the phosphorescence lifetime of the new isomeric platinum complex is longer than that of the reported isomeric platinum complex. As a result, the results here reported show that performing research on the modifications of pyrene rings or functional groups on imine groupl enhances the photophysical properties of pyrene-based materials.

Supplementary Materials: The following are available online at http://www.mdpi.com/2073-4352/10/6/476/s1. CCDC 1575072 contains the supplementary crystallographic data for $\mathbf{2 ( P t ) . ~ T h e s e ~ d a t a ~ c a n ~ b e ~ o b t a i n e d ~ f r e e ~}$ of charge via http://www.ccdc.cam.ac.uk/conts/retrieving.html, or from the Cambridge Crystallographic Data Centre, 12 Union Road, Cambridge CB2 1EZ, UK; fax: (+44) 1223-336-033; or e-mail: deposit@ccdc.cam.ac.uk. Three electronic supplementary informations (ESIs) are available: i.e., ESI-\#1: spectroscopic results; ESI-\#2: X-ray structure report; ESI-\#3: theoretical studies; and CIF-file of 2(Pt), CCDC 1575072.

Author Contributions: Investigation, formal analysis, data curation, writing-original draft preparation, writing-review and editing, X.-D.L.; formal analysis, X.-T.N. All authors have read and agreed to the published version of the manuscript.

Funding: This research received no external funding.

Acknowledgments: This work was supported in part by the Priority Research Program sponsored by the Asian Human Resources Fund from Tokyo Metropolitan Government (TMG) and a National Foundation for Science \& Technology Development (NAFOSTED) grant funded by the Vietnamese Ministry of Science and Technology (Grant No. 104.05-2017.26). L.X.D. appreciates Tokyo Metropolitan University (TMU) for a pre-doctoral fellowship. We appreciate the scientific and supervision support of Ken-ichi Sugiura and Ken-ichi Yamashita (TMU), the quantum yield and lifetime measurements of Yoshitane Imai and Kazuki Nakabayashi, the technical assistance of Toshihiko Sakurai (TMU), and the manuscript checking of Nguyen Hung Huy (VNU University of Science).

Conflicts of Interest: The authors declare no conflict of interest.

\section{References}

1. Williams, J.A.G. Photochemistry and photophysics of coordination compounds: Platinum. Top. Curr. Chem. 2007, 281, 205-268.

2. Chan, S.C.; Chan, M.C.; Wang, Y.; Che, C.M.; Cheung, K.K.; Zhu, N. Organic Light-Emitting materials based on bis(arylacetylide)platinum(II) complexes bearing substituted bipyridine and phenanthroline ligands: Photo- and electroluminescence from 3MLCT excited states. Chemistry 2001, 7, 4180-4190. [CrossRef]

3. Lu, W.; Mi, B.X.; Chan, M.C.; Hui, Z.; Che, C.M.; Zhu, N.; Lee, S.T. Light-emitting tridentate cyclometalated platinum(II) complexes containing $\sigma$-alkynyl auxiliaries: Tuning of photo- and electrophosphorescence. J. Am. Chem. Soc. 2004, 126, 4958-4971. [CrossRef] [PubMed] 
4. Zhu, M.X.; Lu, W.; Zhu, N.; Che, C.M. Structures and solvatochromic phosphorescence of dicationic terpyridyl-platinum(II) complexes with foldable oligo(ortho-phenyleneethynylene) bridging ligands. Chemistry 2008, 14, 9736-9746. [CrossRef]

5. Kui, S.C.; Chow, P.K.; Cheng, G.; Kwok, C.C.; Kwong, C.L.; Low, K.H.; Che, C.M. Robust phosphorescent platinum(II) complexes with tetradentate $\mathrm{O}^{\wedge} \mathrm{N}^{\wedge} \mathrm{C}^{\wedge} \mathrm{N}$ ligands: High efficiency OLEDs with excellent efficiency stability. Chem. Commun. 2013, 49, 1497-1499. [CrossRef]

6. Kozhevnikov, V.N.; Donnio, B.; Bruce, D.W. Phosphorescent, terdentate, liquid-crystalline complexes of platinum(II): Stimulus-dependent emission. Angew. Chem. Int. Ed. 2008, 47, 6286-6289. [CrossRef]

7. Komiya, N.; Itami, N.; Naota, T. Solid-state phosphorescence of trans-bis(salicylaldiminato) platinum(II) complexes bearing long alkyl chains: Morphology control towards intense emission. Chem. Eur. J. 2013, 19,9497-9505. [CrossRef]

8. Komiya, N.; Kashiwabara, T.; Iwata, S.; Naota, T. Synthesis, structure, and solid-state phosphorescence of heteroleptic platinum(II) complexes bearing iminophenyl and iminophenoxy ligands. J. Organomet. Chem. 2013, 738, 66-75. [CrossRef]

9. Komiya, N.; Okada, M.; Fukumoto, K.; Iwata, S.; Naota, T. Solid-state emission enhancement in vaulted transbis(salicylaldiminato)platinum(II) crystals with halogen functionality. Dalton Trans. 2014, 43, 10074-10085. [CrossRef] [PubMed]

10. Komiya, N.; Yoshida, A.; Naota, T. Synthesis and structure of vaulted trans-Bis[1-(2-phenoxy)-imidazol2-ylidene-C2,O]platinum(II) complex. Inorg. Chem. Commun. 2013, 27, 122-126. [CrossRef]

11. Kozhevnikov, D.N.; Kozhevnikov, V.N.; Shafikov, M.Z.; Prokhorov, A.M.; Bruce, D.W.; Williams, J.A. Phosphorescence vs Fluorescence in Cyclometalated Platinum(II) and Iridium(III) Complexes of (Oligo) thienylpyridines. Inorg. Chem. 2011, 50, 3804-3815. [CrossRef] [PubMed]

12. Kozhevnikov, D.N.; Kozhevnikov, V.N.; Ustinova, M.M.; Santoro, A.; Bruce, D.W.; Koenig, B.; Czerwieniec, R.; Fischer, T.; Zabel, M.; Yersin, H. Synthesis of cyclometallated platinum complexes with substituted thienylpyridines and detailed characterization of their luminescence properties. Inorg. Chem. 2009, 48, 4179-4189. [CrossRef] [PubMed]

13. Kozhevnikov, V.N.; Donnio, B.; Heinrich, B.; Bruce, D.W. Morphology-driven absorption and emission colour changes in liquid-crystalline, cyclometallated platinum(II) complexes. Chem. Commun. 2014, 50, 14191-14193. [CrossRef] [PubMed]

14. Spencer, M.; Santoro, A.; Freeman, G.R.; Diez, A.; Murray, P.R.; Torroba, J.; Whitwood, A.C.; Yellowlees, L.J.; Williams, J.A.; Bruce, D.W. Phosphorescent, liquid-crystalline complexes of platinum(ii): Influence of the $\beta$-diketonate co-ligand on mesomorphism and emission properties. Dalton Trans. 2012, 41, 14244-14256. [CrossRef] [PubMed]

15. Zhou, G.J.; Wong, W.Y.; Lin, Z.; Ye, C. White metallopolyynes for optical limiting/transparency trade-off optimization. Angew. Chem. Int. Ed. 2006, 45, 6189-6193. [CrossRef] [PubMed]

16. Zhou, G.; Wong, W.Y.; Poon, S.Y.; Ye, C.; Lin, Z. Symmetric versus unsymmetric platinum(II) bis (aryleneethynylene)s with distinct electronic structures for optical power limiting/optical transparency trade-off optimization. Adv. Funct. Mater. 2009, 19, 531-544. [CrossRef]

17. Hissler, M.; Harriman, A.; Khatyr, A.; Ziessel, R. Intramolecular triplet energy transfer in pyrene-metal polypyridine dyads: A strategy for extending the triplet lifetime of the metal complex. Chem. Eur. J. 1999, 5, 3366-3381. [CrossRef]

18. Lanöe, P.H.; Fillaut, J.L.; Toupet, L.; Williams, J.A.G.; Bozeca, H.L.; Guerchais, V. Cyclometallated platinum(II) complexes incorporating ethynyl-flavoneligands: Switching between triplet and singlet emission induced by selective binding of $\mathrm{Pb}^{2+}$ ions. Chem. Commun. 2008, 36, 4333-4335. [CrossRef]

19. Zhou, G.J.; Wang, Q.; Wong, W.Y.; Ma, D.; Wang, L.; Lin, Z. A versatile color tuning strategy for iridium(III) and platinum(II) electrophosphors by shifting the charge-transfer states with an electron-deficient core. J. Mater. Chem. 2009, 19, 1872-1883. [CrossRef]

20. He, Z.; Wong, W.Y.; Yu, X.; Kwok, H.S.; Lin, Z. Phosphorescent platinum(II) complexes derived from multifunctional chromophores: Synthesis, structures, photophysics, and electroluminescence. Inorg. Chem. 2006, 45, 10922-10937. [CrossRef]

21. Yin, B.; Niemeyer, F.; Williams, J.A.G.; Jiang, J.; Boucekkine, A.; Toupet, L.; Bozec, H.L.; Guerchais, V. Synthesis, structure, and photophysical properties of luminescent platinum(II) complexes containing cyclometalated 4-styryl-functionalized 2-phenylpyridine ligands. Inorg. Chem. 2006, 45, 8584-8596. [CrossRef] [PubMed] 
22. Wong, W.Y.; Ho, C.L. Organometallic photovoltaics: A new and versatile approach for harvesting solar energy using conjugated polymetallaynes. Acc. Chem. Res. 2010, 43, 1246-1256. [CrossRef] [PubMed]

23. Castellano, F.N.; Pomestchenko, I.E.; Shikhova, E.; Hua, F.; Muro, M.L.; Rajapakse, N. Photophysics in bipyridyl and terpyridyl platinum(II) acetylides. Coord. Chem. Rev. 2006, 250, 1819-1828. [CrossRef]

24. Whittle, C.E.; Weinstein, J.A.; George, M.W.; Schanze, K.S. Photophysics of Diimine Platinum(II) Bis-Acetylide Complexes. Inorg. Chem. 2001, 40, 4053-4062. [CrossRef] [PubMed]

25. Hissler, M.; Connick, W.B.; Geiger, D.K.; McGarrah, J.E.; Lipa, D.; Lachicotte, R.J.; Eisenberg, R. Platinum diimine bis(acetylide) complexes: Synthesis, characterization, and luminescence properties. Inorg. Chem. 2000, 39, 447-457. [CrossRef] [PubMed]

26. Han, X.; Wu, L.Z.; Si, G.; Pan, J.; Yang, Q.Z.; Zhang, L.P.; Tung, C.H. Switching between ligand-to-ligand charge-transfer, intraligand charge-transfer, and metal-to-ligand charge-transfer excited states in platinum(II) terpyridyl acetylide complexes induced by $\mathrm{pH}$ change and metal ions. Chem. Eur. J. 2007, 13, 1231-1239. [CrossRef]

27. You, Y.; Park, S.Y. Phosphorescent iridium(III) complexes: Toward high phosphorescence quantum efficiency through ligand control. Dalton Trans. 2009, 8, 1267-1282. [CrossRef]

28. Dien, L.X.; Yamashita, K.; Asano, M.S.; Sugiura, K. Syntheses of a pyrene-based $\pi$-expanded ligand and the corresponding platinum(II) complex, bis[2-[(octylimino)methyl]-1-pyrenolato-N,O] platinum(II). Inorg. Chim. Acta 2015, 432, 103-108. [CrossRef]

29. Dien, L.X.; Yamashita, K.; Sugiura, K. Metal complexes of $\pi$-expanded ligands (2): Synthesis and characterizations of bis[2-[(octylimino)methyl]-1-pyrenolato-N,O] palladium(II) and the stabilized vacant $\mathrm{dx} \mathrm{x}^{2}-\mathrm{y}^{2}$ orbital. Polyhedron 2015, 102, 69-74. [CrossRef]

30. Calvin, M.; Melchior, N.C. Stability of chelate compounds. V. The o-formylnaphthoxide chelates. J. Am. Chem. Soc. 1948, 70, 3273-3275. [CrossRef]

31. Coventry, D.N.; Batsanov, A.S.; Goeta, A.E.; Howard, J.A.; Marder, T.B.; Perutz, R.N. Selective Ircatalysed borylation of polycyclic aromatic hydrocarbons: Structures of naphthalene-2,6-bis(boronate), pyrene-2,7-bis(boronate) and perylene-2,5,8,11-tetra(boronate) esters. Chem. Commun. 2005, 16, 2172-2174. [CrossRef] [PubMed]

32. Crawford, A.G.; Dwyer, A.D.; Liu, Z.; Steffen, A.; Beeby, A.; Palsson, L.O.; Tozer, D.J.; Marder, T.B. Experimental and theoretical studies of the photophysical properties of 2- and 2,7-functionalized pyrene derivatives. J. Am. Chem. Soc. 2011, 133, 13349-13362. [CrossRef] [PubMed]

33. Crawford, A.G.; Liu, Z.; Mkhalid, I.A.; Thibault, M.H.; Schwarz, N.; Alcaraz, G.; Steffen, A.; Collings, J.C.; Batsanov, A.S.; Howard, J.A.; et al. Synthesis of 2- and 2,7-functionalized pyrene derivatives: An application of selective C-H borylation. Chemistry 2012, 18, 5022-5035. [CrossRef] [PubMed]

34. Edkins, R.M.; Fucke, K.; Peach, M.J.; Crawford, A.G.; Marder, T.B.; Beeby, A. Syntheses, structures, and comparison of the photophysical properties of cyclometalated iridium complexes containing the isomeric 1and 2-(2'-pyridyl)pyrene ligands. Inorg. Chem. 2013, 52, 9842-9860. [CrossRef] [PubMed]

35. Ji, L.; Edkins, R.M.; Lorbach, A.; Krummenacher, I.; Bruckner, C.; Eichhorn, A.; Braunschweig, H.; Engels, B.; Low, P.J.; Marder, T.B. Electron delocalization in reduced forms of 2-(BMes 2$)$ pyrene and 2,7-bis(BMes 2$)$ pyrene. J. Am. Chem. Soc. 2015, 137, 6750-6753. [CrossRef] [PubMed]

36. Ji, L.; Fucke, K.; Bose, S.K.; Marder, T.B. Iridium-catalyzed borylation of pyrene: Irreversibility and the influence of ligand on selectivity. J. Org. Chem. 2015, 80, 661-665. [CrossRef]

37. Ji, L.; Lorbach, A.; Edkins, R.M.; Marder, T.B. Synthesis and photophysics of a 2,7-disubstituted donor-acceptor pyrene derivative: An example of the application of sequential Ir-catalyzed C-H borylation and substitution chemistry. J. Org. Chem. 2015, 80, 5658-5665. [CrossRef]

38. Liu, Z.; Wang, Y.; Chen, Y.; Liu, J.; Fang, Q.; Kleeberg, C.; Marder, T.B. Ir-catalyzed direct borylation at the 4-position of pyrene. J. Org. Chem. 2012, 77, 7124-7128. [CrossRef]

39. Harvey, R.G.; Schmolka, S.; Cortez, C.; Lee, H.M. Syntheses of 2-bromopyrene and 2-hydroxypyrene. Synth. Commun. 1988, 18, 2207-2209. [CrossRef]

40. Winkle, M.R.; Ronald, R.C. Regioselective metalation reactions of some substituted (methoxymethoxy)arenes. J. Org. Chem. 1982, 47, 2101-2108. [CrossRef]

41. Dale, T.J.; Sather, A.C.; Rebek, J.J. Synthesis of novel aryl-1,2-oxazoles from ortho-hydroxyaryloximes. Tetrahedron Lett. 2009, 50, 6173-6175. [CrossRef] 
42. Hallett, A.J.; White, N.; Wu, W.; Cui, X.; Horton, P.N.; Coles, S.J.; Zhao, J.; Pope, S.J.A. Enhanced photooxidation sensitizers: The first examples of cyclometalated pyrene complexes of iridium(III). Chem. Commun. 2012, 48, 10838-10840. [CrossRef] [PubMed]

43. Hay, P.J.; Wadt, W.R. Ab initio effective core potentials for molecular calculations. Potentials for K to Au including the outermost core orbitals. J. Chem. Phys. 1985, 82, 299-310. [CrossRef]

44. Gomes, C.S.; Gomes, P.T.; Duarte, M.T.; Paolo, R.E.D.; Macanita, A.L.; Calhorda, M.J. Synthesis, structure, and photophysical characterization of blue-green luminescent zinc complexes containing 2-iminophenanthropyrrolyl ligands. Inorg. Chem. 2009, 48, 11176-11186. [CrossRef] [PubMed]

45. Tsuno, T.; Iwabe, H.; Brunner, H. Synthesis and structural characterization of isomeric palladium(II) complexes with chiral N,O-bidentate ligands. Inorg. Chim. Acta 2013, 400, 262-266. [CrossRef]

46. Dien, L.X.; Truong, N.X.; Quan, N.D.; Yamashita, K.; Sugiura, K. Synthesizing and studying the structure of $\mathrm{Ni}(\mathrm{II})$ complexes containing 2-alkyliminomethyl pyrene ligands. VNU J. Sci. 2018, 34, 16-20.

47. Dien, L.X.; Nga, N.K.; Truong, N.X.; Yamashita, K.; Sugiura, K. Metal complexes of $\pi$-expanded ligands (3): Synthesis and characterization of tris[2-[(octylimino)methyl]-1-pyrenolato-N,O] cobalt(III). VNU J. Sci. 2019, 35, 98-105.

(C) 2020 by the authors. Licensee MDPI, Basel, Switzerland. This article is an open access article distributed under the terms and conditions of the Creative Commons Attribution (CC BY) license (http://creativecommons.org/licenses/by/4.0/). 